\title{
QR-Code tracking and SMS notification transaction interface for scholarship management system
}

\author{
Kenrick Agustin S. Secugal*, Jason P. Sermeno, Nelly E. Mistio \\ College of Computer Studies, University of Antique, Antique, Philippines
}

\begin{abstract}
Information system (IS) is a product of information technology (IT) that supports various business functions utilizing advanced technology comprising hardware, software, people, network, and data. Scholarship management systems is one example of an information system that is designed to assist with the scholarship awarding process of any university. When designing such systems, it is important to consider the reusability of certain components instead of developing an entire software from scratch. In this article, a scholarship management system was developed integrating a quick response code (QR-Code) tracking and short message service (SMS) notification transaction interface. The results of this study showed a high rating from two perspective evaluators with regards to its system functionality, execution, generality as well as its reusability in its source code.
\end{abstract}

Keywords: Helpdesk, Support system, Online support management system, Scholarship management.

\section{OPEN ACCESS}

Received: February 1, 2021

Revised: April 10, 2021

Accepted: May 11, 2021

Corresponding Author: Kenrick Agustin S. Secugal kenrickagustin.secugal@antiquesp ride.edu.ph

Copyright: The Author(s) This is an open access article distributed under the terms of the Creative Commons Attribution License (CC BY 4.0), which permits unrestricted distribution provided the original author and source are cited.

\section{Publisher:}

Chaoyang University of

Technology

ISSN: 1727-2394 (Print)

ISSN: 1727-7841 (Online)

\section{INTRODUCTION}

Education for many is one of the ways to escape from poverty. However, this is not the case for most Filipinos in the country because based on the 2019 annual poverty indicators survey of the Philippine statistics authority, about $12 \%$ of the total population aging 5 years old and over had a college degree or higher, while $2.3 \%$ had no formal education or no grade completed (Mapa, 2020). The survey showed that one of the most common reasons among these youths for not attending school was because of their low financial status. Luckily, there are many institutions and government agencies that offer scholarship programs and other forms of financial aid to Filipino students. These programs provide an opportunity for qualified students to earn a degree and become valuable assets or contributing members of society.

Many institutions today are now equipped with technologies and information systems that manage students' information that includes their scholarship. With the growing demands, consecutive changes on the policies and guidelines, and ineffective management of scholarship grants, there is a need to manage and control the scholarship information of the students. Purchasing an additional information system would not be a cost-effective solution for those institutions that have an existing information system that includes scholarship management modules. Likewise, some institutions could not afford to set up a new information system for their organization.

In order to effectively and efficiently manage the scholarship grants of the students and comply with the Information Organization for Standardization (ISO) standards, documents and record control should be in place.

One of the functional units in a university is the office of student affairs and services (OSAS) whose role is to provide services and programs that promote the quality of student life, meet its needs, and improve learning and success achievements. With its 


\section{International Journal of Applied Science and Engineering}

Secugal et al., International Journal of Applied Science and Engineering, 18(4), 2021039

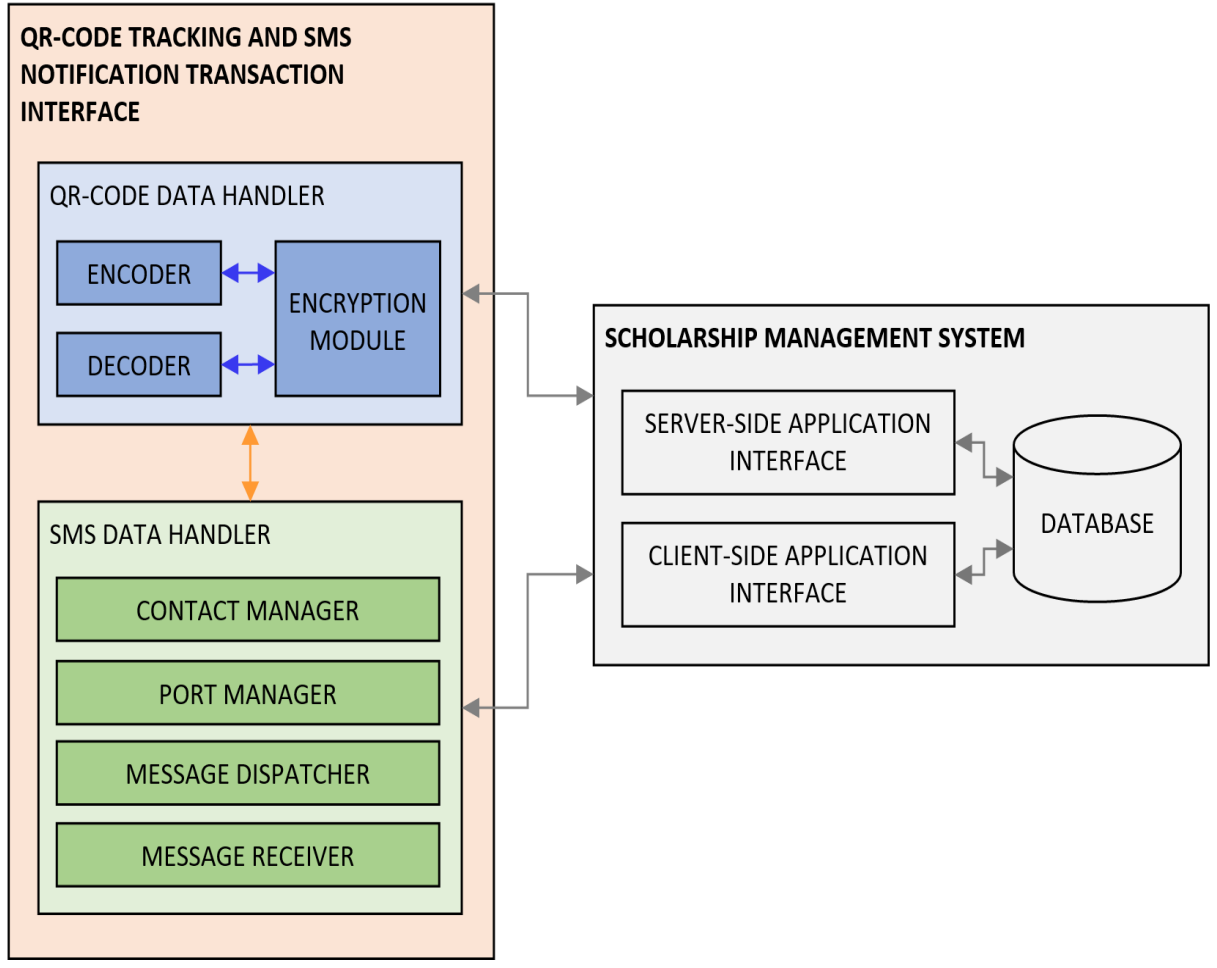

Fig. 1. Conceptual framework of the study

wide scope of services and limited manpower, the office faces many challenges such as difficulty in managing the long queue of students applying for scholarships and grants, rendering overtime jobs to process the voluminous documents in the office, difficulty in disseminating information to scholars and grantees and difficulty in documents and records control particularly data redundancy and security. The database system for OSAS is only limited to managing student scholarships and grants. Varied services in OSAS need more attention aside from processing student scholarships and grants. Thus, some of the OSAS services need to be converted into a computerbased function by developing an information system that would primarily manage student's scholarships and grants (Claro et al., 2013; Fay, 2019), trace documents using QRCode (Intal et al., 2020), and send information via SMS. With this requirement, integration of these functionalities would greatly improve the transaction flow in managing students' scholarships and grants (Secugal, et al., 2020). It is an easier option though - using small printed codes, such as QR codes, around the library that link to resources and information appropriate to their location (Walsh, 2010).

This study is geared towards the development of a QRcode tracking and SMS notification interface to be integrated with the scholarship management system intended for universities or other related institutions. This interface will be designed as a reusable component for any existing information system that utilizes the functionality of QR-Code for tracking and SMS features for communication. Fig. 1 illustrates the conceptual framework of the study where the interface will manage the processing of QR codes and SMS contexts.

\section{METHODOLOGY}

\subsection{Descriptive-Survey}

In order to determine the effectiveness and acceptability, the developed scholarship management system platform had undergone deployment and alpha test in the University of Antique main campus, a university located in the western part of the Philippines, as its test site. Purposive and random sampling was used to conduct surveys and to test the system for the head of units, staff, and scholars of the institution.

To describe the information quality and acceptability of the system, McCall's software quality model instrument and ISO 25010 standard questionnaires for software quality were utilized. McCall's questionnaire was used to evaluate the following system criteria: Correctness, Reliability, Efficiency, Integrity, Usability, Maintainability, Testability, Flexibility, Portability, Reusability, and Interoperability. The ISO questionnaire, on the other hand, was used by nontechnical respondents to evaluate the corresponding system criteria: Functionality, Efficiency, Compatibility, Usability, Reliability, Security, Maintainability, and Portability. Both instruments use a five-point rating scale, where 5 as very high or very good and 1 as very low or poor (Côté et al., 2005). 


\section{International Journal of Applied Science and Engineering}

Secugal et al., International Journal of Applied Science and Engineering, 18(4), 2021039

\subsection{Software Development Model}

With the agile method, the team used the adaptive software development (ASD) model to create and make series of revisions based on end-users' requirements to come up with an effective software system. The model consists of three major phases that include the speculation phase, the collaboration phase, and the learning phase.

In the speculation phase, the goal, scope, limitations, and other requirements of the system based on the functions of OSAS were defined. Fig. 2 illustrates a use case diagram showing the general events and their interaction between actors (director, staff, unit heads, and a scholar) and its interfaces from the initial data gathering. The QR-Code tracking and SMS notification interface were utilized in the system to manage the QR-Code and SMS services. Events such as document control, scholar management, and QRCode tracing are some activities that require such services from the interface.

Based on the use case model, the inputs, outputs, and required processing tasks necessary to transform the inputs to outputs were identified. Fig. 3 describes the InputProcess-Output (IPO) model of the system under study.

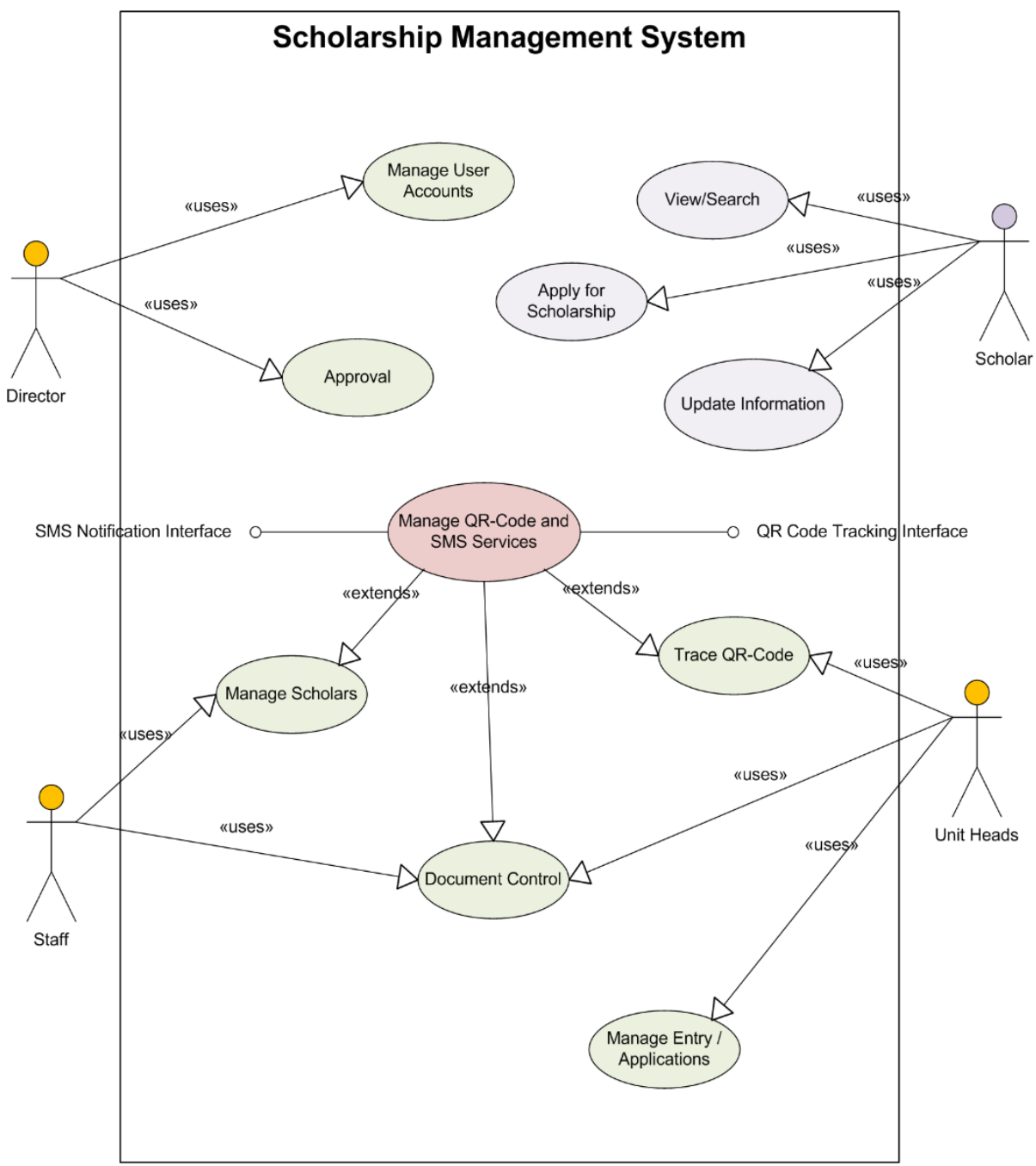

Fig. 2. The use case model of the scholarship management system 


\section{International Journal of Applied Science and Engineering}

Secugal et al., International Journal of Applied Science and Engineering, 18(4), 2021039

\begin{tabular}{|c|c|c|c|}
\hline INPUT & PROCESS & OUTPUT & OUTCOME \\
\hline $\begin{array}{l}\text { SAS Director } \\
\text { User Account } \\
\text { Security Key }\end{array}$ & $\begin{array}{c}\text { SAS Director } \\
\text { Approval } \\
\text { Manage User Accounts }\end{array}$ & $\begin{array}{l}\text { SAS Director } \\
\begin{array}{l}\text { List of Approved } \\
\text { Scholars }\end{array} \\
\text { Reports }\end{array}$ & \\
\hline $\begin{array}{l}\text { Scholars } \\
\text { Student ID Number } \\
\text { Personal Information }\end{array}$ & $\begin{array}{l}\text { Scholars } \\
\text { Encode Information } \\
\text { Viewing }\end{array}$ & $\begin{array}{c}\quad \underline{\text { Scholars }} \\
\text { SMS Notification }\end{array}$ & \\
\hline $\begin{array}{c}\text { SAS Staff } \\
\text { User Accounts } \\
\text { Scholars Information } \\
\text { Scholarship and } \\
\text { Grants Information } \\
\text { Announcement }\end{array}$ & $\begin{array}{c}\text { SAS Staff } \\
\text { Manage Scholarship } \\
\text { Application } \\
\text { Print Reports } \\
\text { Manage Scholarship } \\
\text { Document Control } \\
\text { Send SMS Notification }\end{array}$ & $\begin{array}{c}\text { List of Applied Scholars } \\
\text { List of Scholarships }\end{array}$ & $\begin{array}{c}\text { Scholarship } \\
\text { Management System }\end{array}$ \\
\hline $\begin{array}{l}\text { User Accounts } \\
\text { Entry (Based on Unit } \\
\text { Function) }\end{array}$ & $\begin{array}{c}\text { Unit Heads } \\
\text { Encode Memo / } \\
\text { Communication } \\
\text { Manage Reports } \\
\text { Print Reports } \\
\text { Encode Reports }\end{array}$ & $\begin{array}{l}\text { Unit Heads } \\
\text { Memo / } \\
\text { Communication } \\
\text { Reports } \\
\text { Summary Reports } \\
\text { (Based on Unit } \\
\text { Function) }\end{array}$ & \\
\hline
\end{tabular}

Fig. 3. The Input-Process-Output model of the scholarship management system

In the collaboration phase, the basic information taken from the speculation phase was studied and analyzed to gather complex information needed like what applications to be used, what methods to be applied, and what programming language will be implemented in coding the system (Cashman and Rosenblatt, 2012). This phase also aided in designing and normalizing the database that increased compliance and measures business growth (Reisenwitz, 2019; de Chavez et al., 2015). Fig. 4 depicts an activity diagram describing the dynamic aspects of a series of actions of the scholarship management system. Each user has their own participation, role, and limitations as well as their required inputs and desired outputs in the system.
In the learning phase, the system was designed, coded, and tested. The learning cycles are based on short iterations with design, build, and testing. During these iterations, the knowledge is gathered by making small mistakes based on false assumptions and correcting those mistakes. Thus, activities in this phase led to a greater experience, mastery in the problem domain, and a fitting solution in the system requirements through effective development of the interfaces and integration of various technologies. The developed system was able to become a possible solution to address problems in managing electronic transactions as it provides convenience and lessening errors (Liu et al., 2011). 


\section{International Journal of Applied Science and Engineering}

Secugal et al., International Journal of Applied Science and Engineering, 18(4), 2021039

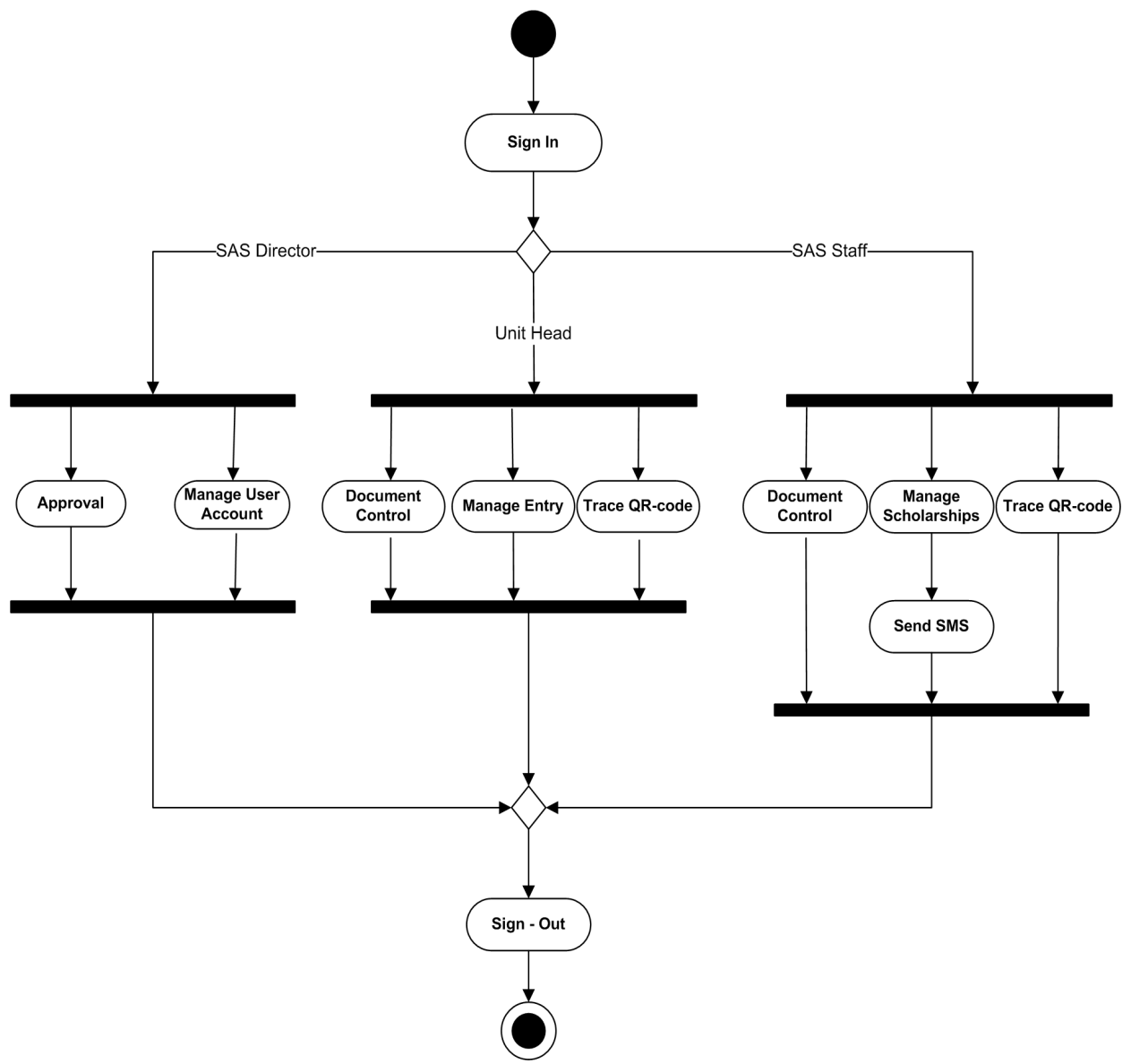

Fig. 4. The activity diagram of the scholarship management system

\section{RESULTS AND DISCUSSION}

The developed scholarship management system was tested at the office of student affairs and services, University of Antique, Sibalom, Antique, Philippines. The system was deployed in a separate server in the management information system (MIS) server room for better simulation and was accessed by the client's account using the school's own existing network. Moreover, each department had a computer for the students to use when they simulated the application.

The first evaluation was conducted using McCall's software evaluation tool among 10 identified IT experts. Fig. 5 is a graph describing the result of the evaluation using the said instrument.
Based on the results, the experts strongly recommend that some operations of the modules must be simplified and some minor documentation on the scripts written in the program must be provided. The experts found that the system was very efficient in terms of system execution, its generality, and reusability in the code. The general mean gathered from the IT experts was 4.24 and interpreted as "Very Good".

The next four evaluations were conducted with the scholars, staff, unit heads, and the director using the ISO/IEC evaluation tool to evaluate the functionality, performance, compatibility, usability, reliability, maintainability, and portability of the system. Fig. 6 depicts the result of the evaluations. 


\section{International Journal of Applied Science and Engineering}

Secugal et al., International Journal of Applied Science and Engineering, 18(4), 2021039

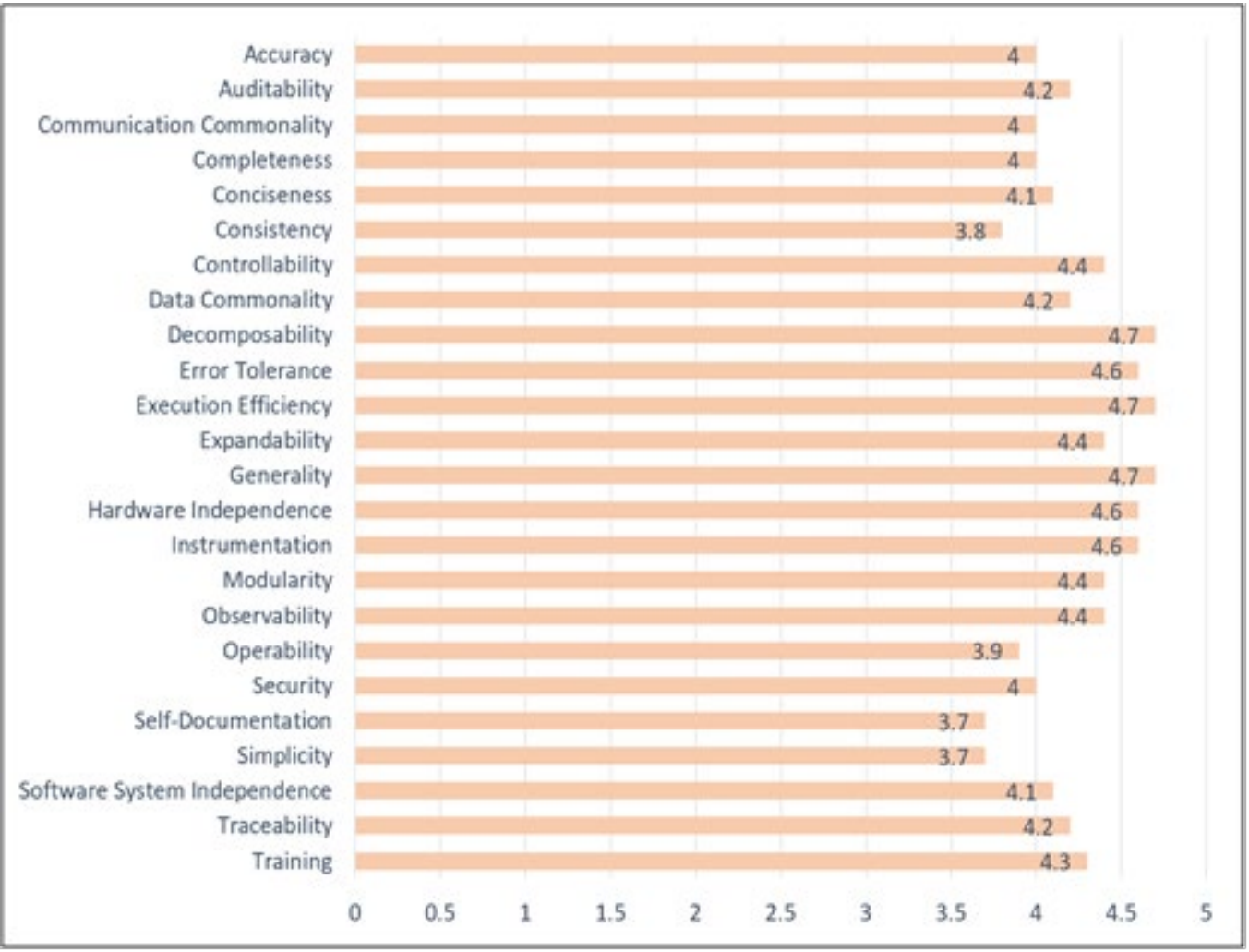

Fig. 5. Result from ten IT experts using McCall's software evaluation

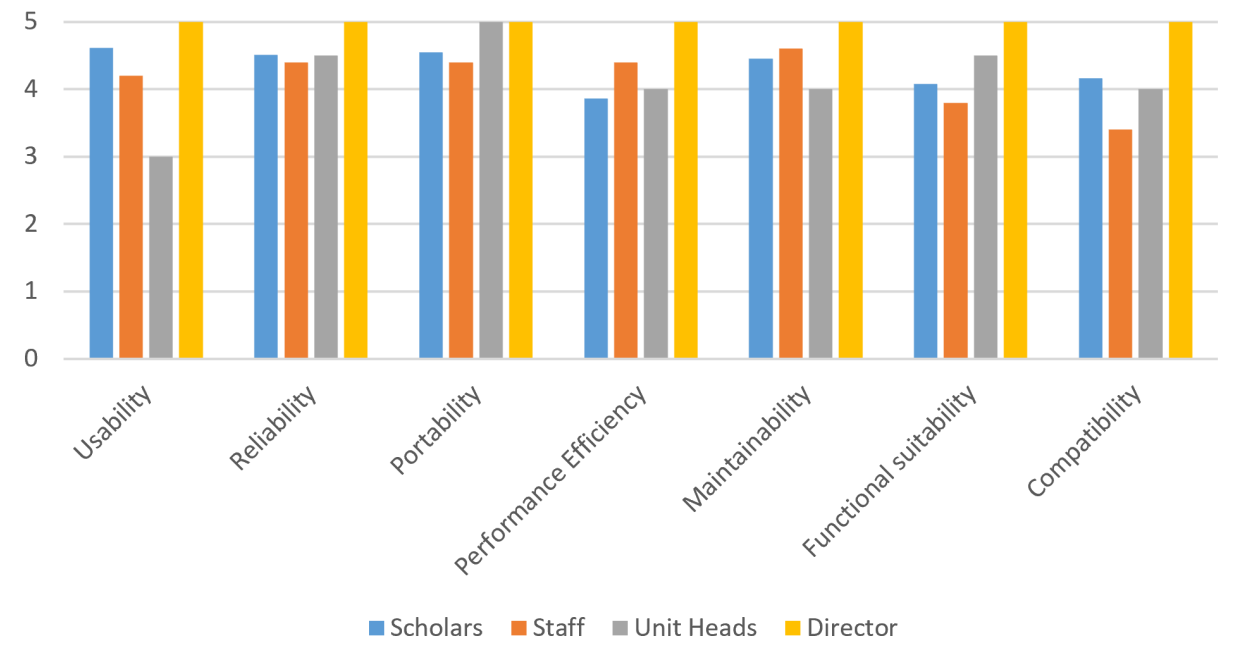

Fig. 6. Result from four groups of evaluators using the ISO/IEC evaluation tool

Based on the result, 49 random scholars rated the system with a general mean of 4.32 with a verbal description "High". Most of the scholars find the system more usable and reliable because it eliminates the hassle of filling up redundant forms and the bottleneck in lining up in the office waiting for their applications to be processed. Meanwhile, the office staff evaluated the system with an average of 4.17 where maintainability is the highest. One of the reasons why these criteria is high because the staff could manage and maintain the scholarship records effectively and efficiently. Although the staff utilizes desktop computers for their daily transactions, they are looking forward to having the system compatible with different browser platforms. The unit heads, particularly the college deans, evaluated the system with a general mean of 4.14 with a verbal description value of "High". The deans find the system high on portability criteria due to its capability of working on different devices as long as it runs on the same browser platforms with ease 


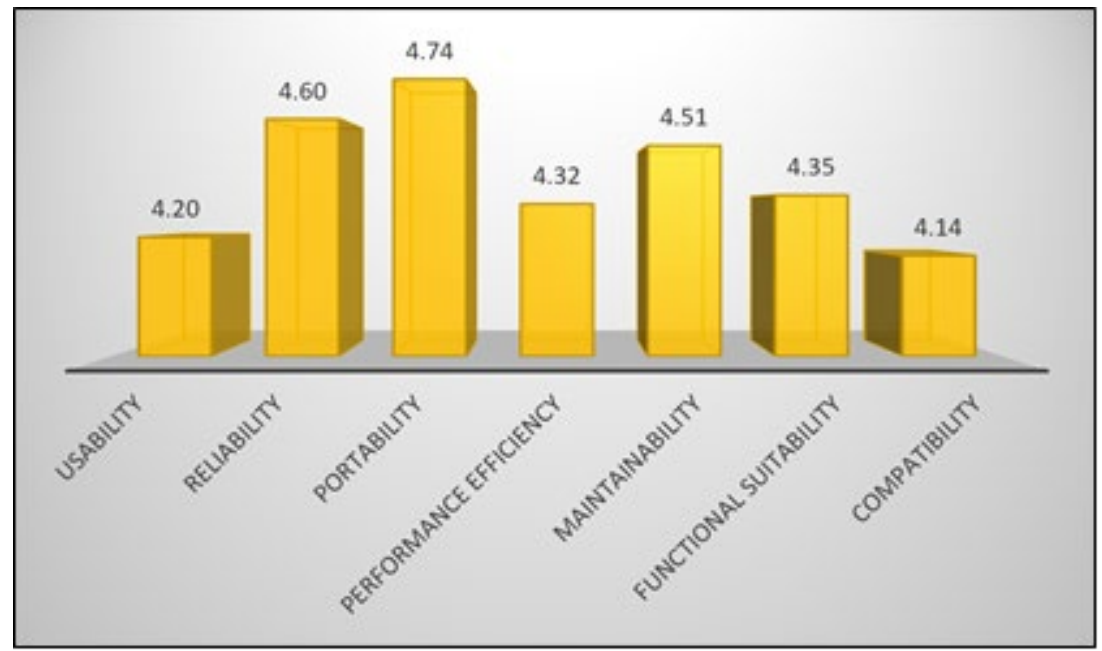

Fig. 7. Overall result from four groups of evaluators

(such as Google Chrome). Most deans commonly use tablet or mobile devices to conduct school-related transactions while they are away from their desktop or personal computers. Lastly, the process owner or the director for the student affairs and services evaluated the system with a general mean of 5.00 as a "Very High" verbal description rating. The reason for this high rating is that the transactions in the office have transitioned from ineffective to effective, efficient, and well-organized transaction flow of managing scholarships and grants to all scholars. This would enable the office to speed up the application process, increase their productivity in a day, and generate accurate reports and statistics required by the top management.

Among the seven criteria, the system gained a higher rating in terms of its portability and reliability. Overall, the conducted evaluation from the client's perspective resulted in the grand mean of 4.41 and described as "High". Fig. 7 describes the overall result from the four groups of evaluators.

\section{CONCLUSION}

The design of the interface of the system was successful and was able to manage the QR-Code and SMS modules efficiently and effectively including the scholarship module. The scholarship application form that was based on the form used was commended by the tester. Students using a dedicated computer for application resulted in a lesser time of application. Application approval and notifying students through SMS was efficient and faster. The document control module with QR-Code technology provided a quicker response to document tracing.

Using the McCalls' software questionnaire, IT experts rated the system "Good", while the ISO/IEC 25010 software evaluation used by the non-technical respondents or the clients gained "High". Therefore, with the positive responses from the tester, the researcher generally concluded that the developed system was accepted and efficient.

For future studies that would include the development of an E-learning system, it is recommended to include an additional SMS feature not only for notifying the students but rather their guardians regarding the status of their scholar. Furthermore, the developed scholarship management system is highly recommended to be used by universities or institutions since it will greatly improve the efficiency in processing scholarship applications and scholarship grants.

\section{ACKNOWLEDGMENT}

This research would like to thank the support and partial funding of University of Antique, Sibalom, Antique, Philippines.

\section{REFERENCES}

Cashman, S., Rosenblatt, H. 2012. System analysis and design. 9th Edition. Boston, USA, Course Technology Cengage Learning.

Claro, D., Libron, K.K., Songcayauon, K., Masillones, J. 2013. Records management information system with SMS notification system. CLOUD, 1, Retrieved from http://ejournals.ph/form/cite.php?id=6114.

Côté, M.A., Suryn, W., Laporte, C.Y., Martin, R.A. 2005. The evolution path for industrial software quality evaluation methods applying ISO/IEC 9126: 2001 quality model: example of MITRE's SQAE method. Software Quality Journal, 13, 17-30. https://10.1007/s11219-0045259-6.

de Chavez, M.A.D., de Ocampo, D.R., Palma, J.L.M., Roca, R.M. 2015. An automate inventory system using quick response $(\mathrm{QR})$ code and barcode for property management of the boys scouts of the Philippines. BS thesis, Mapúa Institute of Technology, Manila, 


\section{International Journal of Applied Science and Engineering}

Secugal et al., International Journal of Applied Science and Engineering, 18(4), 2021039

Philippines. Retrieved from https://docplayer.net/ 41495807-An-automated-inventory-system-using-quickresponse-qr-code-and-barcode-for-property-

management-of-the-boy-scouts-of-the-philippines.html.

Fay, M. 2019. Scholarships and grants for college students. Debt.org. https://www.debt.org/students/scholarshipsand-grants/.

Intal, G.L., Payas, J.D., Fernandez, L.M., Domingo, B.M. 2020. Restaurant information system (RIS) with QR code to improve service operations of casual fine dining restaurant. 2020 IEEE 7th International Conference on Industrial Engineering and Applications (ICIEA), Bangkok, Thailand, 1054-1059, doi: 10.1109/ ICIEA49774.2020.9102036.

Liu, Z., Zeng, Q.L., Wang, C., Lu, Q. 2011. Application research of QRCode barcode in validation of express delivery. In: Shen G., Huang X. (eds) Advanced Research on Electronic Commere, Web Application, and Communication. ECWAC 2011. Communications in Computer and Information Science, 143. Springer, Berlin, Heidelberg. https://doi.org/10.1007/978-3-642-20367156.

Mapa, D. 2020. The 2019 annual poverty indicators survey (2019 APIS). Philippine Statistics Authority. ISSN 01197851. https://psa.gov.ph/content/annual-povertyindicators- survey-apis

Reisenwitz, C. 2019. What is database management? Capterra. https://www.blog.capterra.com/what-isdatabase-management/.

Secugal, K.A., Sermeno, J., Mistio, N. 2020. QR-Code tracking and SMS notification transaction interface for scholarship management system. 2020 International Conference on Innovative Technology Convergence (ICITC 2020). Journal of Innovative Technology Convergence, 2, ISSN No. 2704-4440.

Shelly, G., Rosenblatt, H. 2012. System analysis and design. 9th Edition. Cengage Learning. Boston, USA, Course Technology Cengage Learning. ISBN-13:978-0-53848161-8

Walsh, A. 2010. QR codes - using mobile phones to deliver library instruction and help at the point of need. Journal on Information Literacy, 4, 55-64, 10.11645/4.1.1458. 